\title{
A semiempirical dynamic model of reversible open circuit voltage drop in a PEM fuel cell
}

\author{
Zunyan $\mathrm{Hu}^{1,2}$ (D) | Liangfei $\mathrm{Xu}^{1,2} \mid$ Ziyou Song ${ }^{3} \mid$ Jianqiu $\mathrm{Li}^{1,2} \mid$ Minggao Ouyang ${ }^{1}$
}

\author{
${ }^{1}$ State Key Lab of Automotive Safety and \\ Energy, Tsinghua University, Beijing \\ 100084, China \\ ${ }^{2}$ Collaborative Innovation Center of \\ Electric Vehicles, Beijing, China \\ ${ }^{3}$ Department of Electric Engineering and \\ Computer Science, University of \\ Michigan, Ann Arbor, MI 48109, USA

\section{Correspondence} \\ Jianqiu Li and Liangfei Xu, State Key Lab \\ of Automotive Safety and Energy, \\ Tsinghua University, Beijing 100084, \\ China. \\ Email: lijianqiu@tsinghua.edu.cn; \\ xuliangfei@tsinghua.edu.cn

\section{Funding information} \\ National Natural Science Foundation of \\ China, Grant/Award Number: Grant Nos. \\ 51576113 Grant Nos. U1564209 U1564209 \\ and 51576113; Tsinghua University Initia- \\ tive Scientific Research Program; Beijing \\ Municipal Science \& Technology Com- \\ mission, Grant/Award Number: \\ Z181100004518004; International Science \\ \& Technology Cooperation Program of \\ China, Grant/Award Number: \\ 2016YFE0102200; National Key R\&D \\ Program of China, Grant/Award Number: \\ 2017YFB0102704
}

\begin{abstract}
Summary
Fuel cell voltage modeling is important for fundamental research. The main focus of previous studies has been the working voltage segment, whereas the accuracy of the open circuit voltage (OCV), especially the dynamic OCV change process, has been ignored. A semiempirical model including the OCV and an electrochemical model has been proposed in this study to clarify the reversible voltage drop process. A mixed cathode potential drop that is assumed as corresponding to a piecewise function relationship with an active surface area is introduced in this study. Fitting results exactly coincide with the original data in 2 modes, namely a quasistatic condition in a bench test and a dynamic condition in a fuel cell city bus. In the dynamic OCV drop process, the voltage drop due to the hydrogen crossover current approximately corresponds to $0.003 \mathrm{~V}$ and the mixed cathode potential drop approximately corresponds to $0.02 \mathrm{~V}$.
\end{abstract}

\section{KEYWORDS}

PEM fuel cell, open circuit voltage, reversible voltage drop, voltage model, electrochemical model

\section{1 | INTRODUCTION}

An increase in awareness with respect to environmental pollution and the growing energy crisis have spurred interest in developing new energy technologies. ${ }^{1} \mathrm{~A}$ fuel cell vehicle with its high efficiency, ${ }^{2}$ low environment impact, ${ }^{3}$ and relatively long service life ${ }^{4}$ is recognized by several governments and research institutions as a potential solution. ${ }^{5}$

The most basic research on the fuel cell corresponds to voltage modeling. The output characteristic of a fuel cell is highly nonlinear, ${ }^{6}$ and it depends on several factors including temperature, reactant pressure, membrane hydration, reactant concentrations, and electrical load. With respect to different targets, the characteristics of different fuel cell voltage models are distinguishing.

The static voltage model is widely used as a research mechanism. A model presented by Amphlett et $\mathrm{al}^{7}$ is the most popular model and involves a combination of 4 parts, namely all physical parameters in a fuel cell system, effective pressures of oxygen and hydrogen, temperature, and the concentration of oxygen and hydrogen. The model provides a good mechanism to 
explain the voltage characteristic of a fuel cell. The basis for the study by Amphlett involves a study by Mann et $\mathrm{al}^{8}$ that simplified the activation voltage part and provided a detailed analysis of the parameters. ${ }^{9,10}$ Larminie and Dicks ${ }^{11}$ used empirical equations to describe the voltage current fuel cell characteristic. The results indicate that a fuel cell working in its normal working range exhibits good performance. In this case, the parameters are determined by experimental results. Additionally, internal current is considered in the model, and this is important for voltage estimation in low current periods. A few similar models are also proposed to develop the method. ${ }^{12}$ However, these models are too complex and not applicable. The Chamberline-Kim model $^{13,14}$ neglected internal current $i_{n}$ and combined $i_{0}$ of the tafel equation with the Nernst potential. This model perfectly fits the experimental results. Besides, open circuit voltage (OCV) is also related to temperature and pressure of hydrogen and oxygen ${ }^{15},{ }^{16}$ which makes this problem even more complex.

Parameter identification is an important function for the fuel cell model. The aforementioned models are normally used for OCV estimation, calculating resistance, transfer coefficients, and maximum possible current. In these models, the value of OCV depends on the ambient condition and the fuel cell health state, and this is very useful for system diagnosis. A suitable model that can accurately describe the OCV change is important for system analysis.

The theoretical reversible OCV is higher than its practical value. Vilekar et al ${ }^{17}$ proposed an OCV model to calculate the practical value. The internal current that includes hydrogen crossover current and electrical short-circuit current across the PEM is added to this model. Spinelli et al ${ }^{18,19}$ fitted the initial data with an arbitrary oxidation reaction and then proposed a semiempirical model for hydrogen crossover current estimation. The model also treats the hydrogen crossover current as the main factor for OCV estimation.

Zhang et al ${ }^{20}$ proposed a special OCV estimation model to explain the difference between the theoretical and practical values. In addition to the voltage drop resulting from the hydrogen crossover current, a mixed $\mathrm{OCV}^{21,22}$ was analyzed in this study. They considered the effect of platinum oxide on a catalyst surface and indicated that a voltage drop resulting from the platinum oxide is thrice that of the hydrogen crossover. These results conflict with the results obtained by previous studies. However, the study did not detail a mathematical model to describe the mixed OCV drop.

Kundu et $\mathrm{al}^{23}$ analyzed reversible and irreversible degradation in fuel cells during OCV durability testing. The active surface area decrease ${ }^{24}$ is considered as the main factor that causes the OCV change. However, the study involved simply separating the reversible part from the degradation and did not sufficiently analyze the calculation of the reversible voltage drop.

In conclusion, there is paucity of studies on modeling of OCV and especially on the reversible OCV drop process. The $\mathrm{OCV}$ is an important parameter for system diagnosis. Previous studies built an OCV model by considering hydrogen crossover current, electrical shortcircuit current, and active surface area change. However, the reversible OCV calculation continues to be unclear. It is necessary to clarify the reversible OCV drop model to obtain a more accurate value.

This study proposes a semiempirical model to estimate a reversible fuel cell OCV drop. Section 2 describes the reversible OCV drop process observed in the fuel cell city bus and bench test. Section 3 presents the voltage model and platinum electrochemistry model. A semiempirical part is added to the OCV model. Section 4 presents the model validation and results of the analysis. The model proposed in Section 3 is verified in 2 modes, namely a quasistatic process in the bench test and a dynamic process in a fuel cell city bus. The results indicate that the coefficient of the semiempirical part varies in a reasonable range.

\section{2 | EXPERIMENTAL}

The research group finished a fuel cell city bus demonstration, ${ }^{25}$ and the details of the fuel cell city bus are given in Table 1 and Figure 1A.

While operating the fuel cell city bus, a remarkable reversible OCV drop that lasts for approximately several seconds is observed at every startup phase as shown in Figure 1.

As shown in Figure 1B, an OCV is built in 2 seconds to reach the highest value of $1.02 \mathrm{~V}$ when hydrogen and oxygen are supplied to the anode and cathode. However, the mean OCV drops slowly from 1.02 to $0.98 \mathrm{~V}$ in the

TABLE 1 Parameters of the fuel cell city bus

\begin{tabular}{|lll|}
\hline Column & & Value \\
\hline \multicolumn{1}{c|}{ Length } & & $12 \mathrm{~m}$ \\
\hline Weight & & $18 \mathrm{t}$ \\
\hline \multirow{2}{*}{ Electric motor } & Max power & $150 \mathrm{~kW}$ \\
& Rated power & $75 \mathrm{~kW}$ \\
& Max speed & $2600 \mathrm{r}$ minute ${ }^{-1}$ \\
Fuel cell stack & Max power & $30 \times 2 \mathrm{~kW}$ \\
& Rated power & $25 \times 2 \mathrm{~kW}$ \\
& Cell number & $135 \times 2$ \\
& Monolithic active area & $276 \mathrm{~cm}^{2}$ \\
\hline \multirow{2}{*}{ Power battery } & Capacity & $60 \mathrm{ah} / 34 \mathrm{~kW}$ hour \\
& Rated voltage & $607 \mathrm{~V}$ \\
\hline
\end{tabular}




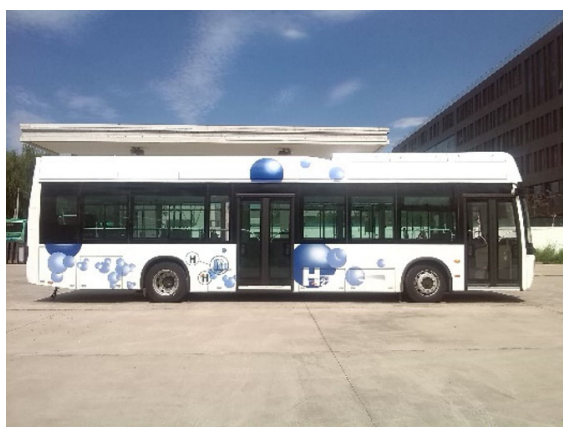

(A) Fuel cell city bus
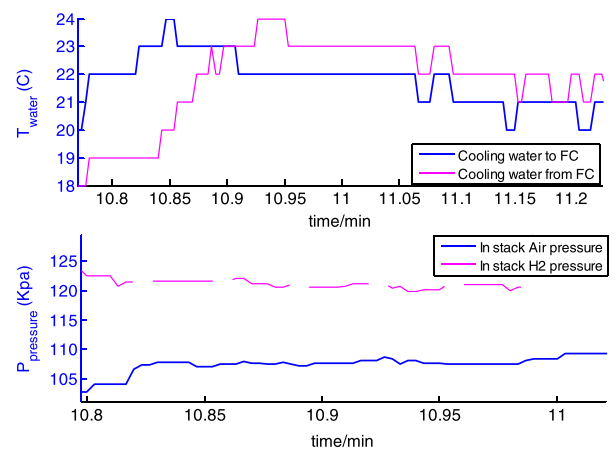

(C) Gas pressure and temperature

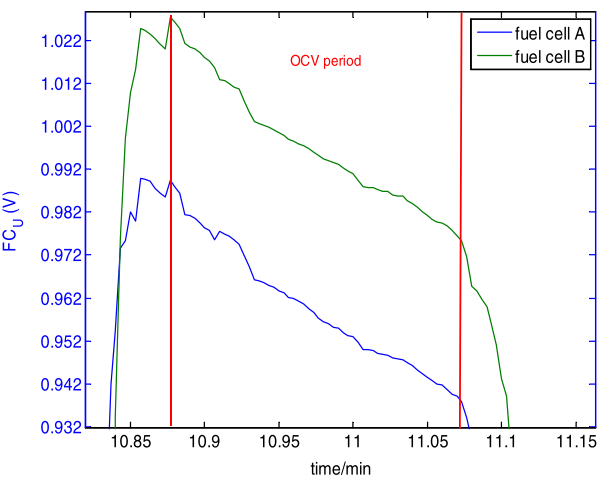

(B) OCV voltage change

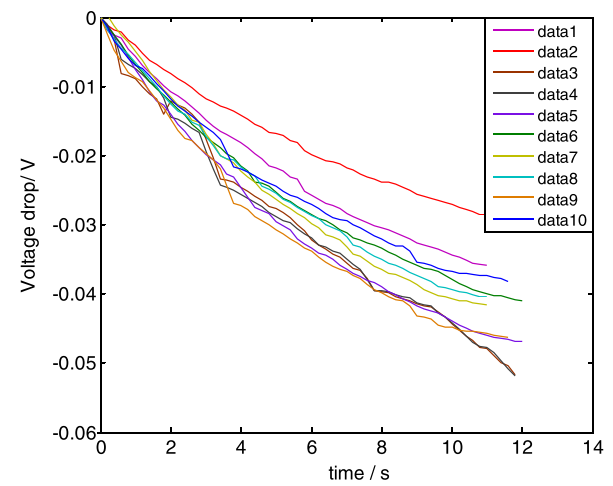

(D) OCV drop comparison

FIGURE 1 Model validation in quasistatic process. A, PtO percentage estimation. B, Reversible voltage drop estimation [Colour figure can be viewed at wileyonlinelibrary.com]

next 10 seconds. This phenomenon reappears again when the fuel cell stack is restarted.

Typically, the fuel cell voltage is determined by the ambient condition and output current. Conversely, with respect to $\mathrm{OCV}$, the output current corresponds to zero, and gas pressure and temperature are stable as shown in Figure $1 \mathrm{C}$. The voltage drop is caused by a change in the internal state of the fuel cell. A more precise model is necessary to explain this phenomenon.

Additional startup data are extracted from the demonstration operation to validate that this phenomenon is not simply accidental. As shown in Figure 1D, 10 sets of startup data of fuel cell city bus are selected to analyze the reversible OCV drop process. There are 2 fuel cell stacks in the city bus connected in a series, and the ambient conditions are different for each day. The voltage drops from the highest voltage point are similar for both fuel cell stacks irrespective of the initial OCV value. The results prove that the phenomenon is repeatable for the bus system.

However, a city bus is characterized by severe working conditions. The environmental temperature is especially completely different between summer and winter. Additionally, the sensors may be inaccurate and unsynchronized. A similar experiment is conducted in the bench test with a 10-cell short stack. An increase in the accuracy of sensor signals in the bench test can create a more stable working condition.

Figure 2A presents the fuel cell test bench. It satisfies the performance requirement of fuel cell test from $100 \mathrm{~W}$ to $10 \mathrm{~kW}$. The test condition is set as shown in Table 2 . All external conditions are fixed in the test bench in contrast to the unstable working condition in the city bus.

As shown in Figure 2B, when output current drops from 10 to $0 \mathrm{~A}$, a similar mean OCV drop of a 10-cell stack is observed in the bench test. The absolute potential decreases slightly when fuel cell stack is held in the OCV condition. The mechanisms of both experiments are evidently the same. Additionally, a few interesting processes that are not included in a traditional OCV model are involved to explain this type of a voltage drop. Extant studies to date have not proposed mathematical models to explain the aforementioned phenomenon.

A fuel cell in an open circuit condition does not output any power. The main difference between OCV condition and normal working condition corresponds to working potential. A catalyst under a high potential can result in the oxidation of platinum, and this may cover the catalyst particle and reduce reaction active sites. ${ }^{26,27}$ This corresponds to a reversible reaction for a platinum particle. 
FIGURE 2 Voltage drop fitting analysis in a dynamic process. A, Voltage fitting and $\mathrm{PtO}$ percentage change. B, Voltage drop of $E_{\text {mix }}^{O C V}$ and $E_{H 2-x c o v e r}^{O C V}$ [Colour figure can be viewed at wileyonlinelibrary.com]

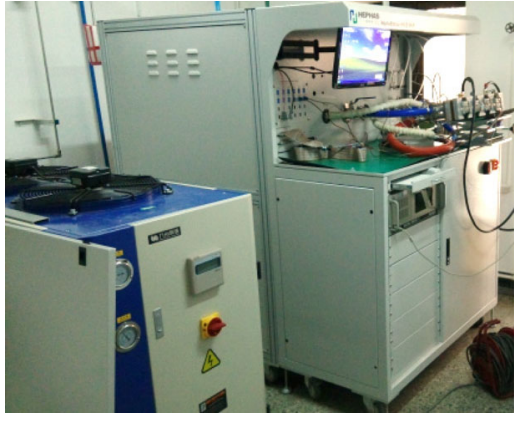

(A) $10 \mathrm{kw}$ fuel cell test bench

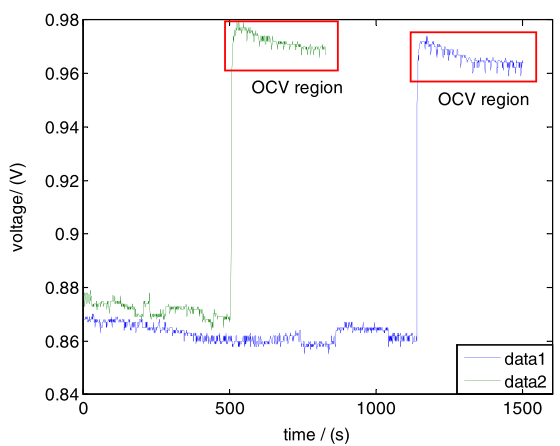

(B) bench test result
TABLE 2 Working conditions in the test bench

\begin{tabular}{ll}
\hline Column & Value \\
\hline Temperature & $60^{\circ} \mathrm{C}$ \\
Cathode stoichiometry & $2.5(>5 \mathrm{~L} /$ minute $)$ \\
\hline Anode stoichiometry & $1.5(>2 \mathrm{~L} /$ minute $)$ \\
\hline Cathode inlet pressure & $103 \mathrm{kPa}$ \\
Cathode outlet pressure & $110 \mathrm{kPa}$ \\
Cathode humidity & $100 \%$ \\
Anode humidity & $100 \%$
\end{tabular}

The chemical reaction in a fuel cell requires the help of a platinum catalyst. It is easy to understand that the reduction of reaction active sites results in the reaction rate drop. Furthermore, the performance drop caused by the ECSA (electrochemical surface area) decrease is validated by several correlation studies.

In conclusion, it is assumed that the reversible OCV drop is related to the reduction of reaction active sites. It is necessary to build an OCV model including the active surface area variation to validate reversible $\mathrm{OCV}$ drop process.

\section{3 | PHYSICAL AND \\ MATHEMATICAL MODELS}

According to the theoretical analysis, the modeling of reversible fuel cell OCV drop is separated into 2 parts. The first part involves the kinetic model of platinum particle reaction, and the second part involves the OCV model to estimate the real time OCV drop.

As shown in Figure 3, the OCV model and platinum electrochemistry model are combined to describe the OCV drop process. It is possible to determine the reversible OCV drop in this model as long as the initial OCV and ambient conditions are given.

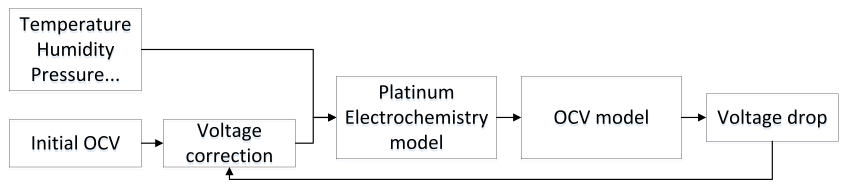

FIGURE 3 Voltage drop fitting for several days of data from a city bus. A, Predicted voltage drop in fuel cell A. B, Predicted voltage drop in fuel cell B [Colour figure can be viewed at wileyonlinelibrary.com]

\section{1 | Semiempirical OCV model}

Numerous studies examine fuel cell modeling. Normally, the fuel cell voltage is divided into 4 parts, namely reversible OCV, voltage loss of ohmic polarization, voltage loss of activation polarization, and voltage loss of concentration polarization. This study mainly focuses on $\mathrm{OCV}$, and therefore, ohmic polarization and activation polarization are ignored.

Based on extant studies, the OCV of a fuel cell is expressed as Equation $1^{20}$ as follows:

$$
E^{O C V}=E_{\text {Theor }}^{O C V}-E_{\text {mix }}^{O C V}-E_{H_{2}-x o v e r}^{O C V}
$$

where $E_{\text {Thoer }}^{O C V}$ denotes reversible OCV and $E_{\text {mix }}^{O C V}$ denotes mixed cathode potential, and this corresponds to a local-cell mechanism that is considered to explain the $\mathrm{Pt}-\mathrm{O}_{2}$ reaction mechanism at the electrode in an $\mathrm{O}_{2}$ saturated acidic solution. ${ }^{20,28}$ Additionally, $E_{H 2-x c o v e r}^{O C V}$ denotes the cathode potential decrease caused by $\mathrm{H}_{2}$ crossover.

Typically, $E_{H 2-x c o v e r}^{O C V}$ is considered as a part of activation polarization that is normally constant. Conversely, for a dynamic process, $E_{H 2-x c o v e r}^{O C V}$ is assumed to be not constant for the active surface area change under OCV conditions. In previous studies, ${ }^{29,30} E_{H 2-x c o v e r}^{O C V}$ is expressed as Equation 2, as follows: 


$$
\begin{aligned}
E_{H_{2} \text {-x cover }}^{O C V} & =V_{a c t}=\frac{R T}{\alpha \mathrm{F}} \ln \left(\frac{i_{H_{2}}^{\text {cross }}}{i_{0}}\right) \\
& =\frac{R T}{\alpha \mathrm{F}} \ln \left(\frac{I_{H_{2}}^{\text {cross }} / E C S A}{i_{0}}\right) \\
& =\frac{R T}{\alpha \mathrm{F}} \ln \left(\frac{I_{H_{2}}^{\text {cross }}}{i_{0} \times E C S A}\right)
\end{aligned}
$$

where $I_{H 2}{ }^{\text {cross }}$ is the absolute crossover current, ECSA denotes the electrochemically active surface areas of a platinum catalyst, and $i_{0}$ denotes the exchange current density. When the operating condition is stable, $i_{0}$, voltage drop of fuel cell OCV combined with $E_{H 2-x c o v e r}^{O C V}$ and $E_{\text {mix }}^{O C V}$ is expressed as Equations 4 and 5 as follows:

$$
\begin{aligned}
& E C S A>E C S A_{0}: \\
& \begin{aligned}
\Delta E^{O C V} & =E_{1}^{O C V}-E_{2}^{O C V}=\Delta E_{\text {mix }}^{O C V}+\Delta E_{H_{2}-\text { xover }}^{O C V} \\
& =\left(E_{\text {mix } 1}^{O C E_{\text {mix } 2}^{O C V}}\right)+\left(V_{\text {act } 2}-V_{\text {act } 1}\right) \\
& =\frac{R T}{\alpha \mathrm{F}} \ln \left(\frac{\left.I_{H_{2}}^{\text {cross }}\right|_{1}}{\left.I_{H_{2}}^{\text {cooss }}\right|_{2}} \times \frac{i_{0} \times\left. E C S A\right|_{2}}{i_{0} \times\left. E C S A\right|_{1}}\right)
\end{aligned}
\end{aligned}
$$

The timescale corresponds to minutes, and thus, $I_{H 2}{ }^{\text {cross }}$ and $i_{0}$ are considered as constant. Hence, $\Delta V_{\text {ocv }}$ is determined by the ECSA change. Based on Equations 4

$$
\begin{aligned}
& E C S A \leq E C S A_{0}: \\
& \begin{aligned}
\Delta E^{O C V}= & E_{1}^{O C V}-E_{2}^{O C V}=\Delta E_{\text {mix }}^{O C V}+\Delta E_{H_{2}-x o v e r}^{O C V}=\left(E_{\text {mix }}^{O C V}-E_{\text {mix } 2}^{O C V}\right)+\left(V_{\text {act } 2}-V_{\text {act } 1}\right) \\
& =\left(\left(1-E C S A_{1} / S_{\text {sum }}\right) \times k_{\text {mix }}-\left(1-E C S A_{2} / S_{\text {sum }}\right) \times k_{\text {mix }}\right)+\left(\frac{R T}{\alpha \mathrm{F}} \ln \left(\frac{i_{H_{2}}^{\text {cros }}}{i_{0}}\right)\left|1-\frac{R T}{\alpha \mathrm{F}} \ln \left(\frac{i_{H_{2}}^{\text {cross }}}{i_{0}}\right)\right|_{2}\right) \\
& =\left(\left(E C S A_{2}-E C S A_{1}\right) / S_{\text {sum }} \times k_{\text {mix }}\right)+\frac{R T}{\alpha \mathrm{F}} \ln \left(\frac{i_{H_{2}}^{\text {cross }}}{i_{0}} \mid 1 \times \frac{i_{0}}{\left.i_{H_{2}}^{\text {cross }}\right|_{2}}\right) \\
& =\left(\left(E C S A_{2}-E C S A_{1}\right) \times k_{\text {mix }}^{\prime}\right)+\frac{R T}{\alpha \mathrm{F}} \ln \left(\left.\frac{I_{H_{2}}^{\text {cross }}}{I_{H_{2}}^{\text {cross }}}\right|_{2} \times \frac{i_{0} \times\left. E C S A\right|_{2}}{i_{0} \times\left. E C S A\right|_{1}}\right)
\end{aligned}
\end{aligned}
$$

$I_{H 2}{ }^{\text {cross }}$, and ECSA are considered as constants.

With respect to $E_{\text {mix }}^{O C V}$, there is no existing mathematical model to describe the voltage drop because of the PtO percentage increase. In the study, it is assumed as a piecewise function in Equation 3. $E C S A_{0}$ is a boundary value that mixed potential has a significant effect; $S_{\text {sum }}$ is the total ECSA without PtO. It is assumed that mixed cathode potential is determined by the percentage of PtO from 0 to $E C S A_{0}$. When it gets larger and larger, the effect of PtO is saturated, and $E_{m i x}^{O C V}$ is regarded as a constant value. The coefficient $k_{\text {mix }}^{\prime}$ corresponds to an empirical parameter and is fitted by using experimental data. The boundary value $E C S A_{0}$ is hard to choose in this study. Therefore, the first part is only used in the startup stage, a dynamic process. When fuel cell is working, it is seen as a static process, and the second part is chosen.

$E_{\text {mix }}^{O C V}= \begin{cases}\theta_{P t O} \times k_{\text {mix }}=\left(1-E C S A / S_{\text {sum }}\right) \times k_{\text {mix }} & E C S A \leq E C S A_{0} \\ \left(1-E C S A_{0} / S_{\text {sum }}\right) \times k_{\text {mix }}=\text { constant } & E C S A>E C S A_{0}\end{cases}$

In conclusion, the platinum particle under high potential is gradually covered by an oxide film, and this may result in a change in $\theta_{P t O}$. Therefore, the reversible and 5, the reversible fuel cell OCV drop is calculated with a certain $E C S A$ reduction.

\section{2 | Platinum electrochemistry model}

Based on electrochemical reactions and the law of substance conservation, the platinum electrochemistry model describes the ECSA changing process and is used in the voltage model.

\subsection{1 | Electrochemical reactions}

The ECSA is related to the chemical reaction of platinum. Extant studies ${ }^{26}$ simplified the chemical reaction of platinum particles under a high potential into the following 3 equations:

$$
\text { Platinum dissolution: } \mathrm{Pt}=\mathrm{Pt}^{2+}+2 \mathrm{e}^{-}
$$

Platinum oxide film formation: $\mathrm{Pt}+\mathrm{H}_{2} \mathrm{O}=\mathrm{PtO}+2 \mathrm{H}^{+}+2 \mathrm{e}^{-}$

Chemical dissolution of platinum oxide: $\mathrm{PtO}+\mathrm{H}^{+}=\mathrm{Pt}^{2+}+\mathrm{H}_{2} \mathrm{O}$ 
Equation 7 denotes the most important process in this study. The catalysis between oxygen and the platinum catalyst is prevented when the platinum particle is covered by an oxide film. A few previous studies consider the oxide as $\mathrm{Pt}(\mathrm{OH})_{2}$. However, $\mathrm{Pt}(\mathrm{OH})_{2}$ converts into $\mathrm{PtO}$ above $0.95 \mathrm{~V}$. Thus, Equation 7 is appropriate for the purposes of this study. Equation 8 does not correspond to a combination of Equations 6 and 7 and is considered as a specific chemical pathway.

\section{3 | Rate equations}

The reaction rate of (6) and (7) is obtained by ButlerVolmer equations. The platinum dissolution rate is shown in Equation 9 as follows:

$$
\begin{gathered}
r_{1}=k_{1} \theta_{v a c}\left[\begin{array}{l}
\exp \left(\frac{\alpha_{a, 1} n_{1} F}{R T}\left(E-U_{1}\right)\right)- \\
\left(\frac{c_{P t^{2+}}}{c_{P t^{2+}, r e f}}\right) \exp \left(-\frac{\alpha_{c, 1} n_{1} F}{R T}\left(E-U_{1}\right)\right)
\end{array}\right] \\
U_{1}=U_{1}^{\ominus}-\frac{1}{2 F} \times \sigma_{P t} M_{P t}{ }_{r}^{-} \rho_{P t}
\end{gathered}
$$

where $r_{1}$ denotes the reaction rate and $U_{1}$ denotes the adjusted thermodynamic Pt dissolution potential. The definitions of the other parameters are given in Table 3.

Similarly, the platinum oxidation reaction is shown in Equation 11 where $r_{2}$ denotes the reaction rate and $U_{2}$ denotes the adjusted thermodynamic Pt oxidation potential. The definition of the other parameters is also given in Table 3.

$$
\begin{array}{r}
r_{2}=k_{2}\left[\begin{array}{c}
\exp \left(-\frac{\omega \theta_{P t O}}{R T}\right) \exp \left(\frac{\alpha_{a, 2} n_{2} F}{R T}\left(E-U_{2}\right)\right)- \\
\theta_{P t O}\left(\frac{c_{H^{+}}^{2}}{c_{H^{+}, r e f}^{2}}\right) \exp \left(-\frac{\alpha_{c, 2} n_{2} F}{R T}\left(E-U_{2}\right)\right)
\end{array}\right] \\
U_{2}=U_{2}^{\ominus}+\frac{1}{2 F} \times\left(\Delta \mu_{P \mathrm{tO}}^{0}+\sigma_{P t O} M_{P t O}^{-} \rho_{P t O}\right)-\frac{1}{2 F} \times \sigma_{P t} M_{P t}{ }_{r} \rho_{P t}
\end{array}
$$

Finally, the third reaction rate is expressed as Equation 13 where $r_{3}$ denotes the reaction rate and $K_{3}$ denotes an equilibrium constant as follows:

$$
r_{3}=k_{3}\left(\theta_{P t O} c_{H^{+}}^{2}-\frac{c_{P t^{2+}}}{K_{3}}\right)
$$

$$
K_{3}=\exp \left[\frac{F}{R T}\left(n_{1} U_{1}-n_{2} U_{2}\right)\right]
$$

Based on the law of mass conservation, the fraction of the platinum surface covered by an oxide, the radius of a platinum particle, and the concentration of $\mathrm{Pt}^{2+}$ are calculated using Equations 15 to 17 as follows:

$$
\begin{gathered}
\frac{d \theta_{P t O}}{d t}=\left(\frac{r_{2}-r_{3}}{\Gamma_{\max }}\right)-\left(\frac{2 \theta_{P t O}}{r}\right) \frac{d r}{d t} \\
\frac{d r}{d t}=-\frac{M}{\rho}\left(r_{1}+r_{2}\right) \\
\varepsilon \frac{d c_{P t^{2+}}}{d t}=4 \pi r^{2} N\left(r_{1}+r_{3}\right)
\end{gathered}
$$

where $\Gamma_{\max }$ denotes the number of moles of active sites per unit of platinum area (it is considered as a constant value). Specifically, it is unreasonable to simply use a constant value to describe the growth of the oxide film. The reduction reaction of oxygen continues to proceed when the theoretical value of $\vartheta_{\text {Pto }}$ corresponds to or exceeds $100 \%$. The percentage of the real active region exceeds $\vartheta_{\mathrm{vac}}$. The assumption of a constant is acceptable to simplify this problem,.

According to Equations 9 to 17, the fraction of the platinum surface covered by oxide and platinum ion concentration is calculated under different potential cycles as shown in Figure 4.

Figure 4A, B shows the relationship between voltage, $\mathrm{PtO}$ percentage, and Pt ion concentration. The potential increase results in a rapid $\mathrm{PtO}$ percentage and $\mathrm{Pt}$ ion increase. Evidently, the reaction rate is sensitive to the potential change.

As shown in Figure 4C, the fraction of the platinum surface covered by $\mathrm{PtO}$ gradually increases under a constant high potential and ultimately reaches a steady value. According to the simulation results, a higher potential leads to a higher fraction and faster response speed, and a reaction time less than 50 seconds continues to be unstable. However, the voltage fluctuation of the OCV condition in Figure 1A is smaller than that in Figure 4. It is ignored for the simulation, and the PtO percentage change continues to constitute a dynamic process.

The parameter and PtO percentage change is used in Equation 4 to obtain the OCV drop value. 
TABLE 3 Parameters of platinum electrochemistry model

\begin{tabular}{|c|c|c|}
\hline Symbol & Parameter & Value \\
\hline$k_{2}$ & Pt oxidation reaction rate constant & $1.36 \times 10^{-7}$ \\
\hline$k_{3}$ & Pt reduction reaction rate constant & $3.2 \times 10^{-20}$ \\
\hline$\theta_{v a c}$ & \multicolumn{2}{|l|}{ The fraction of the platinum surface that not covered by oxide } \\
\hline$\alpha_{a, 1}$ & Anodic transfer coefficient of Pt dissolution reaction & 0.5 \\
\hline$\alpha_{c, 1}$ & Cathodic transfer coefficient of Pt dissolution reaction & 0.5 \\
\hline$\alpha_{a, 2}$ & Anodic transfer coefficient of Pt oxide reaction & 0.35 \\
\hline$\alpha_{c, 2}$ & Cathodic transfer coefficient of Pt oxide reaction & 0.15 \\
\hline$C_{H+}$ & \multicolumn{2}{|l|}{$\mathrm{H}^{+}$concentrate } \\
\hline$C_{P t 2+, r e f}$ & Reference platinum ion concentration & $1000 \mathrm{~mol} / \mathrm{m}^{3}$ \\
\hline$C_{H+, r e f}$ & Reference $\mathrm{H}^{+}$concentrate & $1000 \mathrm{~mol} / \mathrm{m}^{3}$ \\
\hline$U_{1}^{\ominus}$ & Standard thermodynamic potential of Pt dissolution & $1.188 \mathrm{~V}$ \\
\hline$U_{2}^{\theta}$ & Standard thermodynamic potential of Pt oxidation & $0.98 \mathrm{~V}$ \\
\hline$\sigma_{P t}$ & Surface tension of $\mathrm{Pt}$ & $2.37 \mathrm{~J} / \mathrm{m}^{2}$ \\
\hline$\sigma_{P t O}$ & Surface tension of $\mathrm{PtO}$ & $1 \mathrm{~J} / \mathrm{m}^{2}$ \\
\hline$M_{P t}$ & Molecular weight of Pt & $0.1951 \mathrm{~kg} / \mathrm{mol}$ \\
\hline
\end{tabular}

\section{4 | Modeling procedure}

The solution of the coupled equations is based on the discrete element method. How to choose a suitable discrete time step is important for numerical calculation stability. Based on the electrochemical principle, a lower potential requires a shorter step to avoid the swing of reaction rate. Commercial software MatLab R2017a is used to implement the equations on a personal computer with Inter Core i5 $2.60 \mathrm{GHz}$ CPU and 8.00 GB RAM.

\section{4 | MODEL VALIDATION AND RESULT ANALYSIS}

When a fuel cell starts from $0 \mathrm{~V}$ to $\mathrm{OCV}$, the fraction of the platinum surface covered by PtO increases from $0 \%$ to $70 \%$. This corresponds to a dynamic process as discussed in Section 3.2 during the initial several seconds. As shown in Figure 1, the OCV data from the city bus is too short and continues to correspond to a dynamic process. Given that the working condition in the bench test is significantly more stable and repeatable, the bench test results are given priority over other results to simplify this problem. Subsequently, the dynamic voltage drop process is analyzed by a semiempirical model.

\section{Quasistatic process in test bench}

To reduce the effect of the gas filling process at the beginning of the OCV condition, the fuel cell stack continues to output a small current for several minutes and then turns to the OCV condition.

Based on the mathematical model in Section 3, the voltage drop due to the ECSA decrease is divided into 

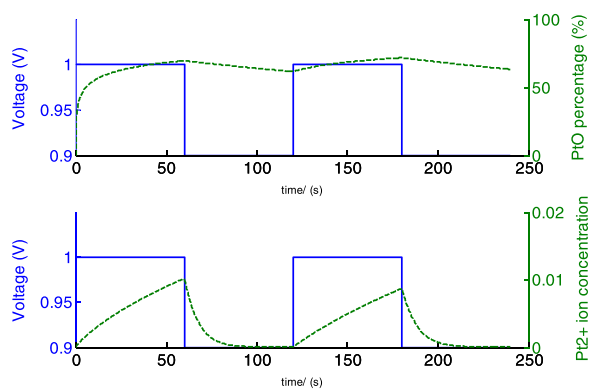

(A) Characteristics of platinum under a square wave voltage cycle
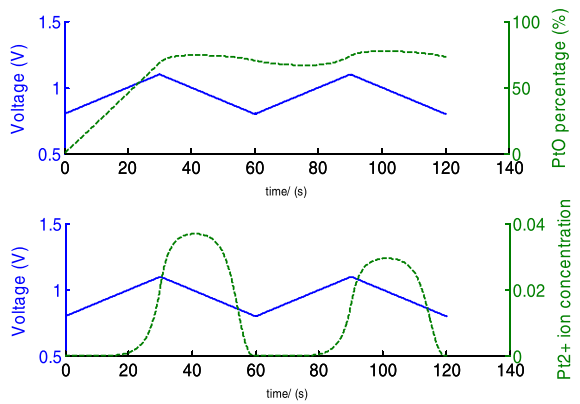

(B) Characteristics of platinum under a triangular wave voltage cycle

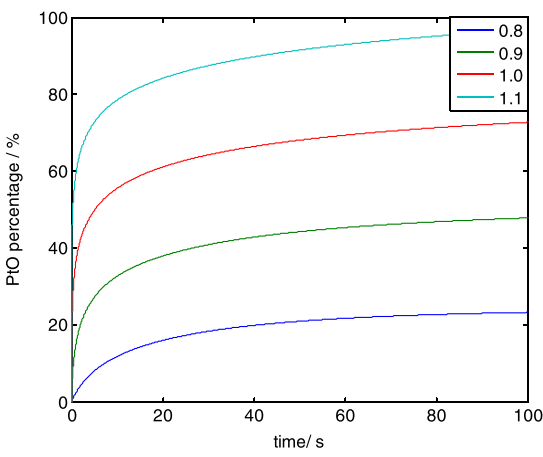

(C) PtO change under constant voltage

FIGURE 4 Highest fuel cell potential in each data set [Colour figure can be viewed at wileyonlinelibrary.com]

$E_{m i x}^{O C V}$ and $E_{H 2-x c o v e r}^{O C V}$. Conversely, for the bench test in this study, the PtO percentage increase in the OCV condition is milder than a normal startup process, and thus, $E_{\text {mix }}^{O C V}$ is ignored in the bench test part. Based on Equation 5, OCV change is expressed as Equation 18.

$$
\Delta E^{O C V}=\frac{R T}{\alpha \mathrm{F}} \ln \left(\frac{\left.E C A\right|_{2}}{\left.E C A\right|_{1}}\right)
$$

where $R, \alpha, F$, and $T$ are constants, and ECSA is obtained from a platinum electrochemistry model. Therefore, a forward calculation result is directly obtained in the quasistatic process. The estimation results are shown in Figure 5.

Figure 1A shows that the fuel cell works in 2 voltage steps, when the output current drops from 10 to $0 \mathrm{~A}$. As shown in Equation 14, the PtO percentage increases to a stable value at each voltage step. It is evidently considered as a quasistatic process in the OCV region. In the switching process, the PtO percentage increases from approximately $40 \%$ to $70 \%$. Furthermore, the OCV value exhibits significant drop.

Similar experiments were conducted twice to validate the OCV model. Figure 1B shows the twice reversible OCV drop process. The voltage drop is perfectly repeatable in the bench test.

With respect to the mathematical model, the fitting results of Equation 18 coincide exactly with the original data shown in Figure 1B. The results indicate that the OCV drop is determined by the ECSA change and that Equation 18 accurately estimates the reversible OCV drop in a quasistatic process.

\section{Dynamic process in city bus}

When compared with the OCV drop in a quasistatic process, the voltage drop in a dynamic process is significantly higher. With respect to a dynamic process, the PtO percentage increases rapidly, and it is impossible to ignore the effect of the mixed cathode potential change. Therefore, the semiempirical model presented as Equation 3 is added to the voltage drop model to explain the OCV change. The least squares algorithm is used to confirm the value of $k_{\text {mix }}^{\prime}$ in Equation 5. The structure of the least squares algorithm for the
FIGURE 5 Model validation in quasistatic process [Colour figure can be viewed at wileyonlinelibrary.com]

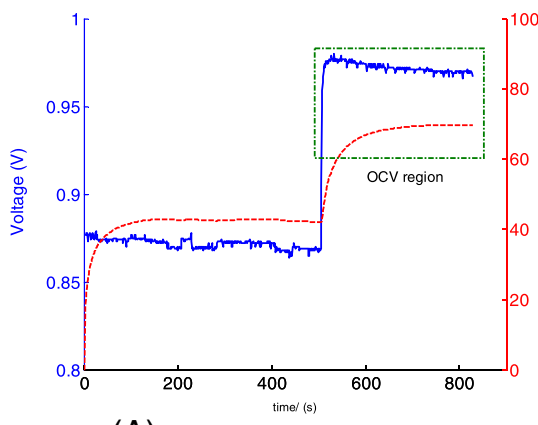

(A) PtO percentage estimation

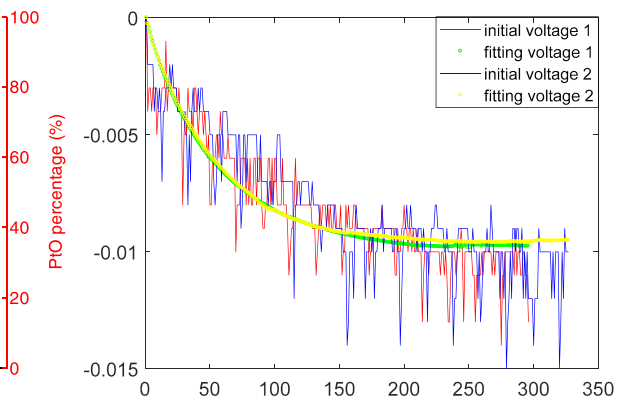

(B) Reversible voltage drop estimation 
semiempirical dynamic model is shown in Equations 19 to 22 as follows:

$$
\begin{aligned}
\Delta E^{O C V} & =\left(\left(E C S A_{2}-E C S A_{1}\right) \times k_{\text {mix }}^{\prime}\right)+\frac{R T}{\alpha \mathrm{F}} \ln \left(\frac{\left.I_{H_{2}}^{\text {cross }}\right|_{1}}{\left.I_{H_{2}}^{\text {cross }}\right|_{2}} \times \frac{i_{0} \times\left. E C S A\right|_{2}}{i_{0} \times\left. E C S A\right|_{1}}\right) \\
& =\Delta E C S A \times k_{\text {mix }}^{\prime}+\Delta E_{H_{2}-x \text { cover }}
\end{aligned}
$$

$$
\Delta E^{O C V}=\left(\Delta E C S A \Delta E_{H_{2}-x \mathrm{cover}}\right)\left(\begin{array}{l}
k_{\text {mix }}^{\prime} \\
1
\end{array}\right)
$$

$$
\mathbf{U}_{\mathrm{ocv}}=\mathbf{H}_{\mathrm{n}} \theta_{\mathrm{n}}
$$

$$
\begin{aligned}
\theta_{\mathrm{n}} & =\left(\begin{array}{l}
k_{\text {mix }}^{\prime} \\
1
\end{array}\right) \quad \text { and } \mathbf{H}_{\mathrm{n}} \\
& =\left(\begin{array}{l}
\left.\left.\Delta E C S A\right|_{1} \Delta E_{\mathrm{H}_{2}-x \mathrm{cover}}\right|_{1} \\
\left.\Delta E C S A\right|_{2} \Delta E_{\mathrm{H}_{2}-\left.x \mathrm{cover}\right|_{2}} \\
\cdots \\
\left.\left.\Delta E C S A\right|_{n} \Delta E_{\mathrm{H}_{2}-x \mathrm{cover}}\right|_{n}
\end{array}\right) \text { and } \mathbf{U}_{\mathrm{ocv}} \\
& =\left(\begin{array}{l}
\left.\Delta E^{O C V}\right|_{1} \\
\left.\Delta E^{O C V}\right|_{2} \\
\cdots \\
\left.\Delta E^{O C V}\right|_{n}
\end{array}\right)
\end{aligned}
$$

where $\mathbf{H}_{\mathbf{n}}$ denotes an input vector, $\boldsymbol{\theta}_{\mathbf{n}}$ denotes the target vector to solve, and $\mathbf{U}_{\mathbf{o c v}}$ denotes the OCV drop vector. The least squares results $\widehat{\theta_{\mathbf{n}}}$ for $\theta_{\mathbf{n}}$ are calculated using Equations 23 to 25 as follows:

$$
\theta_{n}=\left(\mathbf{H}_{n}^{T} \mathbf{H}_{n}\right)^{-1} \mathbf{H}_{n}^{T} \mathbf{U}_{\mathrm{ocv}}
$$
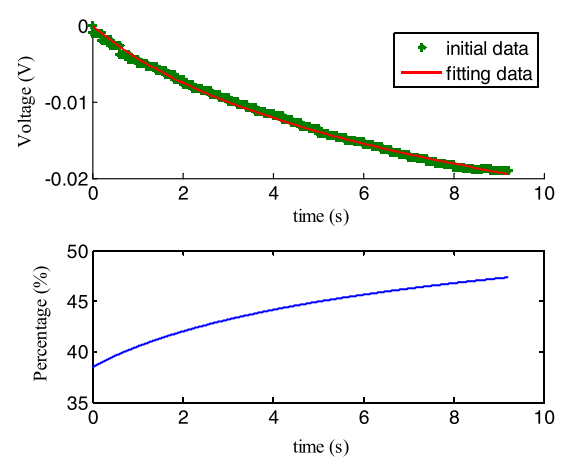

(A) Voltage fitting and PtO percentage change

$$
\begin{gathered}
\mathbf{U}_{O C V}=\mathbf{H}_{n} \theta_{n} \\
\varepsilon_{n}=\max _{i=1, \ldots, N}\left|\frac{\left.\Delta E^{O C V}\right|_{n, \mathrm{i}}}{\left.\Delta E^{O C V}\right|_{i}}\right| \\
n_{\mathrm{opt}}=\arg \min _{n} \varepsilon_{n}
\end{gathered}
$$

where $\varepsilon_{\mathrm{n}}$ denotes the estimation deviation, $\left.\Delta \widehat{E^{\widehat{O C V}}}\right|_{\mathrm{n}, \mathrm{i}}$ denotes the predicted value with $\widehat{\theta_{\mathbf{n}}}$, and $\Delta E^{O C V}$ denotes the actual OCV drop. Furthermore, $n_{\text {opt }}$ denotes the best least square solution to minimize $\varepsilon_{\mathrm{n}}$, and this indicates a least square solution for $k_{m i x}^{\prime}$.

As shown in Figure 5B, when the reaction gas is supplied to the fuel cell, the voltage increases from $0 \mathrm{~V}$ to the highest voltage point with increases in gas pressure. To rule out the impact of gas pressure, the highest potential point is set as the starting point to analyze the voltage drop process. The fitting results are shown in Figure 6.

Figure 6A shows that OCV decreases with respect to time. Additionally, the descent speed corresponds to $0.02 \mathrm{~V} / 10$ seconds and is significantly faster than that of bench test that corresponds to $0.01 \mathrm{~V} / 300$ seconds. The $\mathrm{PtO}$ percentage increases from $38 \%$ to $47 \%$ in less than 10 seconds, and this is also faster than the result of the bench test. Based on Equation 5, the fitting result also perfectly coincides with the original data.

Figure 6B further illustrates the voltage drop of each part. The mixed cathode potential drop is 5 times $E_{H 2-x c o v e r}^{O C V}$, which is validated in the quasistatic process. Given the increase in $\mathrm{PtO}$, the balance of $\mathrm{Pt}-\mathrm{O}_{2}$ reaction is broken, and the reversible OCV shifts to a lower value, thereby resulting in an increase in $E_{\text {mix }}^{O C V}$.

However, it is difficult to conclude as to whether this phenomenon is repeatable. In this study, 16 sets of reversible OCV drop data from the fuel cell city bus are used to validate the dynamic mode. The value of $k_{\text {mix }}^{\prime}$

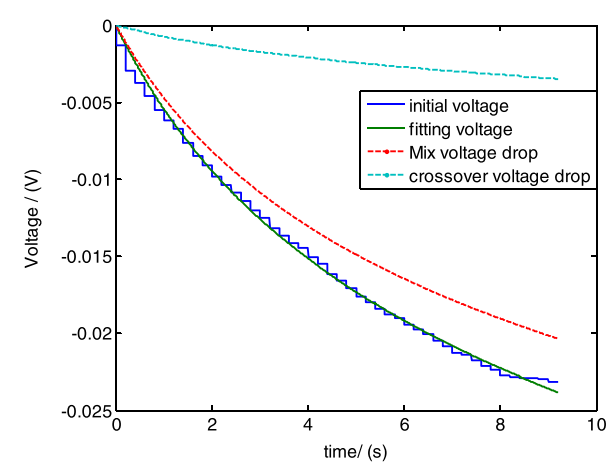

(B) Voltage drop of $\mathrm{E}_{\text {mix }}^{O C V}$ and $\mathrm{E}_{H 2-x c o v e r}^{O C V}$

FIGURE 6 Voltage drop fitting analysis in a dynamic process [Colour figure can be viewed at wileyonlinelibrary.com] 
is obtained from the above fitting results, and it approximately corresponds to -0.300 for fuel cell $\mathrm{A}$ and -0.174 for fuel cell $\mathrm{B}$. The model validation results are shown in Figure 7.

As shown in Figure 7A, B, the prediction reversible OCV drop is close to the original data. Additionally, the fitting deviations are acceptable for the mathematical model. This implies that the credibility of the fitting result $k_{\text {mix }}^{\prime}$ is validated and that the reversible OCV drop process is adequately described by the semiempirical model.
However, the potential drop rates are different for the 2 fuel cell stacks. The fitting result of $k_{\text {mix }}^{\prime}$ for fuel cell A approximately corresponds to -0.3 , and that for fuel cell $\mathrm{B}$ approximately corresponds to -0.17 (which is half that of fuel cell A). Although it is difficult to explain as to why the OCV drop rate for fuel cell $\mathrm{A}$ is generally higher than that of fuel cell B, it is finally attributed to the difference between the fuel cell structure and initial OCV.

Figure 8 shows the initial OCV value of the fuel cell stack. The voltage of fuel cell B is higher than that of fuel

(A)
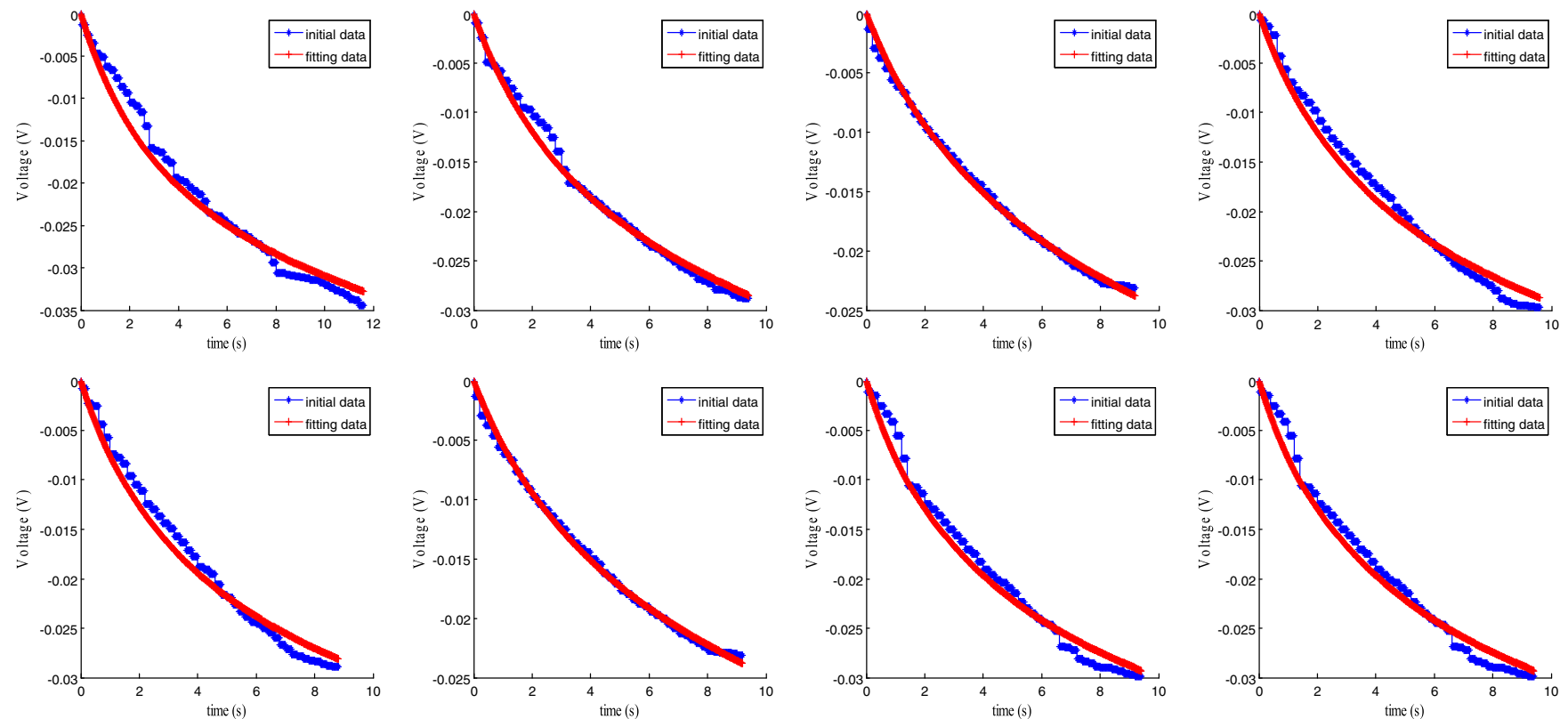

(B)
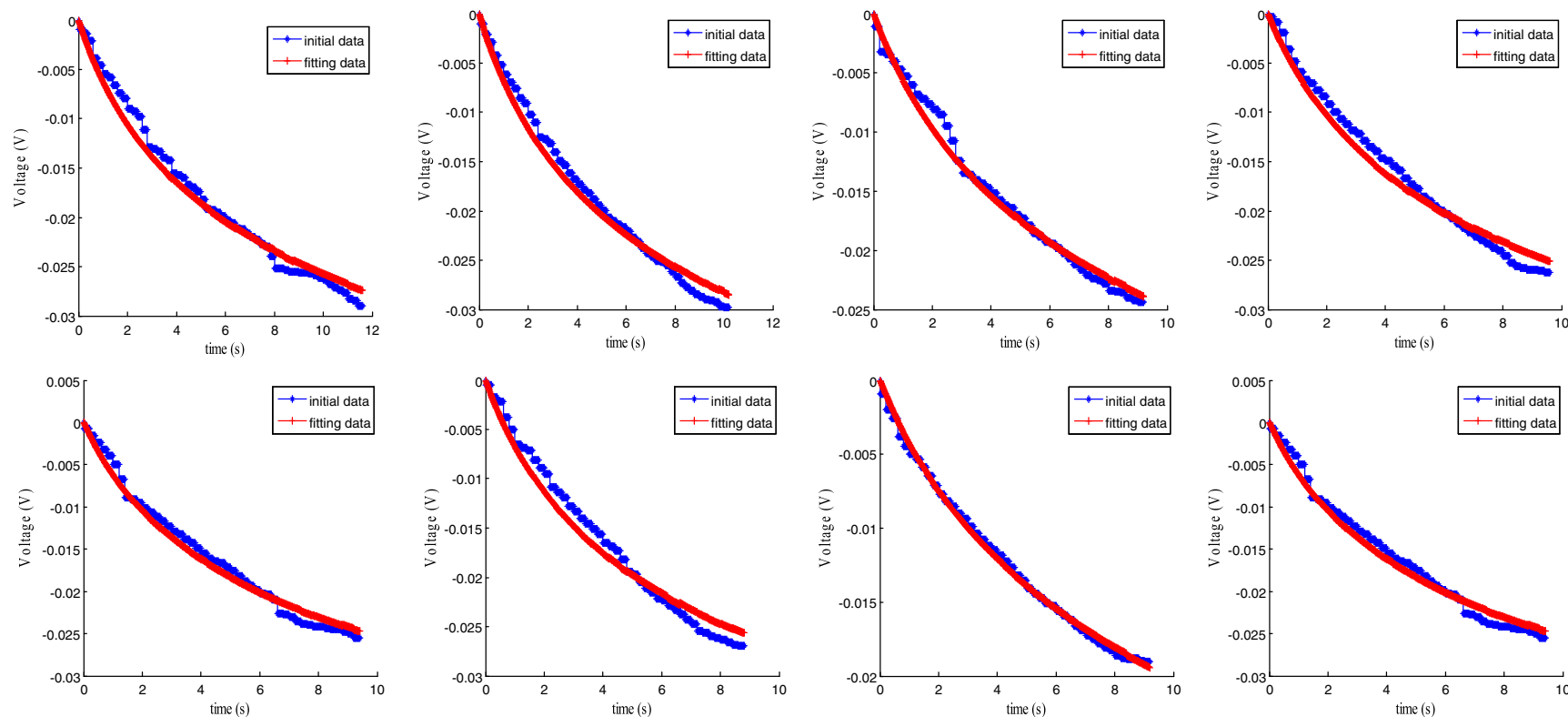

FIGURE 7 Voltage drop fitting for several days of data from a city bus [Colour figure can be viewed at wileyonlinelibrary.com] 


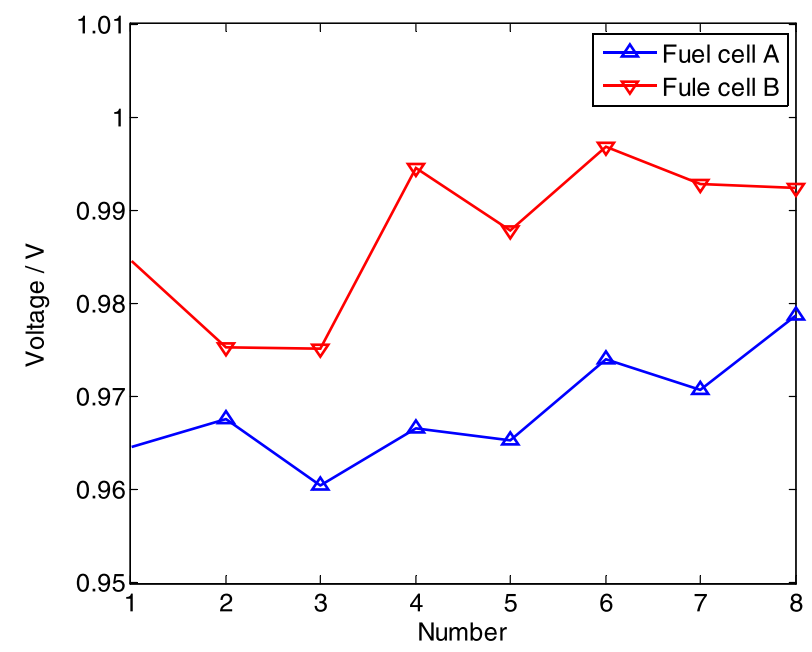

FIGURE 8 Highest fuel cell potential in each data set [Colour figure can be viewed at wileyonlinelibrary.com]

cell A. As shown in Equation 7 and Figure 4C, an increase in the initial voltage leads to a faster achievement of a stable value and shortens the dynamic process. Therefore, the voltage drop of mixed cathode potential can reach the stable value faster when the initial OCV is high and when the dynamic process is short. Given the quasistatic process in the bench test, $k_{\text {mix }}^{\prime}$ is considered as 0 in the model, and a perfect fitting result is obtained. This verifies that a longer dynamic process results in a higher $k_{m i x}^{\prime}$.

However, it is difficult to propose a model that predicts the value of $k_{m i x}^{\prime}$. The reversible OCV drop is very complex. A future study that considers the effect of absolute $\mathrm{OCV}$ value is needed to optimize the semiempirical model.

\section{5 | CONCLUSION}

This study analyzes reversible OCV drop in a startup process. A semiempirical model combined with an OCV and an electrochemical model is proposed to explain this phenomenon. The voltage drop is attributed to the following 2 reasons: $E_{H 2-x c o v e r}^{O C V}$ and $E_{\text {mix }}^{O C V}$. A new model for $E_{\text {mix }}^{O C V}$ is proposed in the present study and is verified in 2 modes.

With respect to a quasistatic process in the bench test, the reversible OCV drop only corresponds to $0.01 \mathrm{~V}$ in 5 minutes. The voltage decrease because of $E_{H 2-x c o v e r}^{O C V}$ coincides exactly with the original data, and this perfectly validates the assumption of a decrease in the OCV.

With respect to a dynamic process in the city bus, the voltage increases from 0 to $1 \mathrm{~V}$ in 2 seconds, and the complete dynamic process lasts only for approximately
10 seconds. The voltage drop because of $E_{\text {mix }}^{O C V}$ constitutes most of the reversible OCV drop. To describe the aforementioned phenomenon, it is assumed that $E_{\text {mix }}^{O C V}$ exhibits a linear relationship with ECSA. The semiempirical model perfectly fits the dynamic voltage drop process, and the fitting results are used to validate repeatability for 2 fuel cell stacks over several days.

The validation results of 2 fuel cell stacks are different but repeatable. The OCV drop rate for fuel cell A is typically higher than that of fuel cell B. An increase in the initial OCV can lead to a faster dynamic process, and thus, it is assumed that a higher initial OCV results in a lower $k_{m i x}^{\prime}$. Conversely, with respect to the quasistatic process in the bench test, the value of $k_{\text {mix }}^{\prime}$ is considered as 0 when PtO dynamic change process is ignored.

Future research will examine a mechanism model of $E_{\text {mix }}^{O C V}$ to optimize a semiempirical model. Additionally, the relationship between $k_{m i x}^{\prime}$ and initial OCV will be explored further.

\section{ACKNOWLEDGEMENTS}

This work was supported by the National Key R\&D Program of China (No. 2017YFB0102704), National Natural Science Foundation of China (Nos. 51576113 and U1564209), International Science \& Technology Cooperation Program of China (No. 2016YFE0102200), Beijing Municipal Science \& Technology Commission (No. Z181100004518004), and Tsinghua University Initiative Scientific Research Program.

\section{ORCID}

Zunyan Hu (D) http://orcid.org/0000-0002-1438-3693

\section{REFERENCES}

1. Song Z, Hofmann H, Li J, Hou J, Han X, Ouyang M. Energy management strategies comparison for electric vehicles with hybrid energy storage system. Appl Energy. 2014;134:321-331.

2. Morse JD. Micro-fuel cell power sources. International Journal of Energy Research. 2007;31(6-7):576-602.

3. Ahmadi P, Kjeang E. Realistic simulation of fuel economy and life cycle metrics for hydrogen fuel cell vehicles. International Journal of Energy Research. 2017;41(5):714-727.

4. Barbir F, Yazici S. Status and development of PEM fuel cell technology. International Journal of Energy Research. 2008;32(5):369-378.

5. Hörmandinger G, Lucas NJ. An evaluation of the economics of fuel cells in urban buses. International Journal of Energy Research. 1997;21(6):495-525. 
6. Ay M, Midilli A, Dincer I. Exergetic performance analysis of a PEM fuel cell. International Journal of Energy Research. 2006;30(5):307-321.

7. Amphlett JC. Performance modeling of the Ballard mark iv solid polymer electrolyte fuel cell. J Electrochem Soc. 1995;142(1):9-15.

8. Mann RF, Amphlett JC, Hooper MAI, Jensen HM, Peppley BA, Roberge PR. Development and application of a generalised steady-state electrochemical model for a pem fuel cell. $J$ Power Sources. 2000;86(1-2):173-180.

9. Amphlett JC, Baumert RM, Mann RF, Peppley BA, Roberge PR, Rodrigues A. Parametric modelling of the performance of a $5 \mathrm{kw}$ proton-exchange membrane fuel cell stack. J Power Sources. 1994;49(1):349-356.

10. Chang KY, Lin HJ, Chen PC. The optimal performance estimation for an unknown pemfc based on the Taguchi method and a generic numerical pemfc model. Int $J$ Hydrogen Energy. 2009;34(4):1990-1998.

11. Larminie, J., \& Dicks, A. L. (2013). Fuel cell systems explained.

12. Sadli I. Modélisation par impédance d'une pile à combustible pem pour utilisation en électronique de puissance. Vandoeuvre-les-Nancy. In: INPL; 2006.

13. Kim J, Lee SM, Srinivasan S, Chamberlin CE. Modelling of proton exchange fuel cell membrane with an empirical equation. $J$ Electrochem Soc. 1995;142(8):2670-2674.

14. Busquet S, Hubert CE, Labbe J, Mayer D, Metkemeijer R. A new approach to empirical electrical modelling of a fuel cell, an electrolyser or a regenerative fuel cell. $J$ Power Sources. 2004;134(1):41-48.

15. Xing L, Das PK, Song X, Mamlouk M, Scott K. Numerical analysis of the optimum membrane/ionomer water content of PEMFCs: The interaction of Nafion ${ }^{\circledR}$ ionomer content and cathode relative humidity. Appl Energy. 2015;138:242-257.

16. Ismail MS, Hughes KJ, Ingham DB, Ma L, Pourkashanian M. Effects of anisotropic permeability and electrical conductivity of gas diffusion layers on the performance of proton exchange membrane fuel cells. Appl Energy. 2012;95:50-63.

17. Vilekar SA, Datta R. The effect of hydrogen crossover on opencircuit voltage in polymer electrolyte membrane fuel cells. $J$ Power Sources. 2010;195(8):2241-2247.

18. Spinelli P, Francia C, Ambrosio EP, Lucariello M. Semi-empirical evaluation of PEMFC electro-catalytic activity. $J$ Power Sources. 2008;178(2):517-524.

19. Francia C, Ijeri VS, Specchia S, Spinelli P. Estimation of hydrogen crossover through Nafion ${ }^{\circledast}$ membranes in PEMFCs. $J$ Power Sources. 2011;196(4):1833-1839.
20. Zhang J, Tang Y, Song C, Zhang J, Wang H. PEM fuel cell open circuit voltage (OCV) in the temperature range of $23 \mathrm{C}$ to $120 \mathrm{C}$. $J$ Power Sources. 2006;163(1):532-537.

21. Parthasarathy A, Srinivasan S, Appleby AJ, Martin CR. Temperature dependence of the electrode kinetics of oxygen reduction at the platinum/Nafion ${ }^{\circledR}$ interface- a microelectrode investigation. J Electrochem Soc. 1992;139(9):2530-2537.

22. Parthasarathy A, Dave B, Srinivasan S, Appleby AJ, Martin CR. The platinum microelectrode/Nafion interface: An electrochemical impedance spectroscopic analysis of oxygen reduction kinetics and Nafion characteristics. $J$ Electrochem Soc. 1992;139(6):1634-1641.

23. Kundu S, Fowler M, Simon LC, Abouatallah R. Reversible and irreversible degradation in fuel cells during open circuit voltage durability testing. J Power Sources. 2008;182(1):254-258.

24. Neyerlin KC, Gasteiger HA, Mittelsteadt CK, Jorne J, Gu W. Effect of relative humidity on oxygen reduction kinetics in a PEMFC. J Electrochem Soc. 2005;152(6):A1073-A1080.

25. Li J, Hu Z, Xu L, et al. Fuel cell system degradation analysis of a Chinese plug-in hybrid fuel cell city bus. Int J Hydrogen Energy. 2016;41(34):15295-15310.

26. Darling RM, Meyers JP. Kinetic model of platinum dissolution in PEMFCs. J Electrochem Soc. 2003;150(11):A1523-A1527.

27. Bi W, Fuller TF. Modeling of PEM fuel cell Pt/C catalyst degradation. J Power Sources. 2008;178(1):188-196.

28. Thacker R, Hoare JP. Sorption of oxygen from solution by noble metals: I. Bright platinum. J Electroanal Chem Interfacial Electrochem. 1971;30(1):1-14.

29. Hu Z, Li J, Xu L, et al. Multi-objective energy management optimization and parameter sizing for proton exchange membrane hybrid fuel cell vehicles. Energ Conver Manage. 2016;129:108-121.

30. Kundu, S. (2008). Development and application of a chemical degradation model for reinforced electrolyte membranes in polymer electrolyte membrane Fuel Cell Diss Abstr Int, Volume: 69-11, Section: B, page: 6980.

How to cite this article: $\mathrm{Hu} \mathrm{Z,} \mathrm{Xu} \mathrm{L,} \mathrm{Song} \mathrm{Z}, \mathrm{Li}$ J, Ouyang M. A semiempirical dynamic model of reversible open circuit voltage drop in a PEM fuel cell. Int J Energy Res. 2019;43:2550-2561. https:// doi.org/10.1002/er.4127 